\title{
Differences in gene expression related to the outcomes of obesity treatment, peak oxygen uptake, and fatty acid metabolism measured in a cardiopulmonary exercise test
}

\author{
Marta Gruchała-Niedoszytko', Pieter van der Vlies', Piotr Niedoszytko², Bahram Sanjabi", \\ Marek Niedoszytko ${ }^{3}$, Małgorzata Kaczkan¹, Magdalena Pieszko1, Katarzyna Gierat-Haponiuk², \\ Aleksandra Śliwińska', Dominika Szalewska², Sylwia Małgorzewicz ${ }^{1}$ \\ 1 Department of Clinical Nutrition, Medical University of Gdańsk, Gdańsk, Poland \\ 2 Department of Medical Rehabilitation, Medical University of Gdańsk, Gdańsk, Poland \\ 3 Department of Allergology, Medical University of Gdańsk, Gdańsk, Poland \\ 4 Department of Genetics, The University Medical Center Groningen, Groningen, the Netherlands
}

\section{KEY WORDS}

cardiopulmonary exercise testing, gene expression, obesity
Correspondence to:

Marta Gruchała-Niedoszytko, MD, Zakład Żywienia Klinicznego i Dietetyki Gdański Uniwersytet Medyczny, ul. M. Skłodowskiej 3a, 80-210 Gdańsk Poland, phone: +4858349 2723 email:mg@gumed.edu.pl Received: December 13, 2017. Revision accepted: March 25, 2018 Published online: March 26, 2018 Conflict of interest: none declared. Pol Arch Intern Med. 2018;

128 (5): 280-286 doi:10.20452/pamw.4228 Copyright by Medycyna Praktyczna Kraków 2018

\section{ABSTRACT}

INTRODUCTION The obesity pandemic requires development of methods that could be used on a large scale, such as the cardiopulmonary exercise test (CPET). Gene expression may explain CPET results on the molecular level.

OBJECTIVES The aim of this study was to compare gene expression in obesity, depending on CPET results. PATIENTS AND METHODS The study group consisted of 9 obese patients and 7 controls. The treatment encompassed diet, rehabilitation, and behavioral therapy. Diet was based on the body composition analyzed by bioelectrical impedance, resting metabolic rate, and subjective patient preferences. The rehabilitation depended on the CPET results: maximal oxygen uptake and fatty acid metabolism. Behavioral intervention focused on the diagnosis of health problems leading to obesity, lifestyle modification, training in self-assessment, and development of healthy habits. The intensive treatment lasted for 12 weeks and consisted of consultations with a physician, dietitian, and medical rehabilitation specialist. RNA was isolated from the whole blood. A total of 47323 transcripts were analyzed, of which 32379 entities were confirmed to have high quality of RNA.

RESULTS We observed differences in gene expression related to the CPET results indicating abnormalities in fat oxidation and maximal oxygen uptake. The genes with major differences in expression were: CLEC12A, HLA-DRB1, HLA-DRB4, HLA-A29.1, IFIT1, and LOC100133662.

CONCLUSIONS The differences in gene expression may account for the outcomes of treatment related to inflammation caused by obesity, which affects the muscles, fat tissue, and fatty acid metabolism.

INTRODUCTION Obesity has become a pandemic of modern societies. The World Health Organization defines obesity as abnormal and excessive accumulation of fat tissue that presents a risk to health. As a complex systemic disease, it leads to metabolic, endocrine, and cardiopulmonary dysfunction of multiple organs. The main cause of obesity is excessive caloric intake and limited physical activity. Recent data on air pollution and metabolic disruptors indicate an additional environmental risk. ${ }^{1}$ Interestingly, the prevalence of obesity has increased in almost all countries. ${ }^{2}$ Between 1980 and 2016, the prevalence among men has increased from $28.8 \%$ to $39 \%$ (boys, $8.1 \%$ to $19 \%$ ), and among women, from $29.8 \%$ to $40 \%$ (girls, $8.4 \%$ to $18 \%$ ). The worldwide prevalence of obesity has tripled since $1975 .{ }^{2}$ Global data are similar to the epidemiology of the disease reported in Poland, where $33.4 \%$ of the population are obese and $36.7 \%$, overweight. ${ }^{3}$ The comparison of 
the results of the Polish studies WOBASZ (conducted in 2003-2005) and WOBASZ II (conducted in 2013-2014) showed a shift of the body mass index category to higher values in both sexes and an increase in obesity rates among men. ${ }^{4}$ Obesity is related to an increased risk of several diseases, the most serious being coronary artery disease, stroke, and cancer, which lead to increased mortality in obese patients..$^{5-7}$

Current treatment of obesity can be divided into different steps including: 1) lifestyle modification programs based on diet, exercise, and behavioral intervention ${ }^{8-10}$; 2) pharmacotherapy $^{11,12}$; and 3) bariatric surgery. ${ }^{13,14}$ The magnitude of the obesity pandemic requires development of methods that could be used on a large scale, which is difficult to achieve with bariatric treatment. Methods that could improve lifestyle modification programs are therefore under investigation, including the cardiopulmonary exercise test (CPET). ${ }^{15,16}$

The CPET is an exercise test combined with an analysis of the respiratory gas exchange concentration. The test measures the response and function of the circulatory, respiratory, and neurologic systems, as well as skeletal muscles and metabolism during physical exercise. The crucial analyzed value is maximal oxygen uptake during exercise training of maximal intensity $\left(\mathrm{VO}_{2 \max }\right){ }^{17,18}$ The most important parameter analyzing fat metabolism is fatty acid metabolism (FAT) expressed as $\mathrm{g} / \mathrm{h}$. It measures the maximal fat mass, which is metabolized over a certain time and which differs according to sex and exercise intensity. Moreover, it is a patient-specific value. ${ }^{16,17}$ FAT heart rate (HR) is a parameter that enables an assessment of the heart rate at which fat metabolism is maximal. FAT HR is approximately in the mean (SD) range of $58 \%$ (3\%) of the maximal heart rate. It occurs before the anaerobic threshold point, where anaerobic metabolism dominates aerobic fat metabolism. ${ }^{16}$ An analysis of fat oxidation, including the assessment of the optimal exercise intensity providing optimal fat metabolism, improves obesity treatment. ${ }^{15,16}$

The analysis of gene expression enables an assessment of the functioning of transcripts and their role in biological processes. The whole genome expression enables a study of the function of the most important transcripts. Studies on gene expression in obesity have shown differences related to diet and bariatric treatment. ${ }^{19-22}$ The differences were found in fat tissue, ${ }^{20}$ muscles, and peripheral blood. 22-24 This may be explained by systemic inflammation observed in obesity, which is related to systemic inflammation influencing the function of muscles in fat metabolism..$^{20,21}$

Combining CPET and gene expression assessment allows a unique insight into obesity pathology and treatment mechanisms, leading to an optimized treatment strategy. The CPET indicates the systemic differences in response to exercise. The observed changes in the CPET may be correlated with differences in gene expression.
Additionally, the results of the obesity treatment using lifestyle modification differ significantly. We hypothesized that changes in gene expression observed in peripheral blood cells related to treatment outcomes may be similar to the changes related to different CPET results, which may help elucidate why some patients do not benefit from the treatment.

The aim of the study was to compare gene expression in lean and obese patients, to examine differences in gene expression related to CPET results, and to evaluate changes in gene expression related to results of obesity treatment in an intensive lifestyle modification program.

PATIENTS AND METHODS Obese patients treated at the Department of Clinical Nutrition, Medical University of Gdańsk, Poland, who were excluded from bariatric treatment received an option of an intensive lifestyle modification program including diet, physical exercise, and behavioral therapy. The study was performed in the years from 2012 to 2014 . The inclusion criteria were body mass index of $30 \mathrm{~kg} / \mathrm{m}^{2}$ or higher, age of 18 years or older, and lack of contraindications to diet treatment, physical rehabilitation, and exercise. The exclusion criteria were neoplastic, autoimmune, and active infectious diseases and chronic heart, liver, and renal failure. The following diseases were considered a contraindication to the treatment: heart, respiratory, renal, and liver insufficiency, other neoplastic or chronic diseases leading to an impaired ability for physical exercise, pregnancy, or lack of compliance.

The size of the study group was assessed using the Altman nomogram ${ }^{25}$ with an assumption that gene expression profile characteristics for obesity may be found in $90 \%$ of obese and $10 \%$ of lean patients, with a test power of 0.8 and a $P$ value of less than 0.05 . The estimated number of studied patients was above 12 .

The treatment protocol consisted of diet intervention, exercise, and behavioral therapy. Diet intervention was based on the body composition analyzed by bioelectric impedance, resting metabolic rate, and subjective patient preferences. The intensity of the exercise was tailored according to the CPET results, mainly $\mathrm{VO}_{2 \max }, \mathrm{FAT} \mathrm{g} / \mathrm{h}$, and FAT HR. Behavioral intervention was focused on the diagnosis of health problems leading to obesity, lifestyle modification, training in self-assessment, and development of healthy habits. The intensive treatment lasted for 12 weeks and consisted of consultations with a physician, dietitian, and medical rehabilitation specialist. The CPET and bioelectric impedance were performed before and after the treatment. The first part of the exercise, which lasted 6 weeks, was performed at the outpatient department of medical rehabilitation, while further rehabilitation treatment was performed by patients at home.

The CPET was performed with a LodeCorival cycloergometer (Lode B.V., Groningen, 
TABLE 1 Clinical data of obese patients and controls participating in the gene expression study

\begin{tabular}{|c|c|c|c|c|c|}
\hline $\begin{array}{l}\text { Subject } \\
\text { age, y; sex }\end{array}$ & $\begin{array}{l}\text { Body mass } \\
\text { reduction }>10 \% \\
\text { of the initial } \\
\text { weight }\end{array}$ & \multicolumn{2}{|c|}{$\begin{array}{l}\text { FAT, g/h } \\
\text { Incorrect: }<20 \\
\text { Correct: } \geq 20\end{array}$} & \multicolumn{2}{|c|}{$\begin{array}{l}\mathrm{V}_{2 \max ^{\prime}} \mathrm{ml} / \mathrm{min}^{\mathrm{b}} \\
\text { Incorrect: }<1.7 \\
\text { Correct: } \geq 1.7\end{array}$} \\
\hline \multicolumn{6}{|l|}{ Controls } \\
\hline 25 ; female & - & 14 & 0 & 2.3 & 1 \\
\hline 24; male & - & 47 & 1 & 3.7 & 1 \\
\hline 24; male & - & 26 & 1 & 2.7 & 1 \\
\hline 25; female & - & 40 & 1 & 3.9 & 1 \\
\hline 25; male & - & 34 & 1 & 3.4 & 1 \\
\hline 25; male & - & 22 & 1 & 3.6 & 1 \\
\hline 21 ; female & - & 12 & 0 & 1.28 & 0 \\
\hline \multicolumn{6}{|c|}{ Obese patients } \\
\hline 41; male & No & 13 & 0 & 1.5 & 0 \\
\hline 35; male & Yes & 26 & 1 & 2.1 & 1 \\
\hline 33; female & Yes & 16 & 0 & 1.7 & 1 \\
\hline 35; female & Yes & 3 & 0 & 1.2 & 0 \\
\hline 47; male & Yes & 16 & 0 & 1.2 & 0 \\
\hline 41 ; female & Yes & 6 & 0 & 1.5 & 0 \\
\hline 40; female & No & 6 & 0 & 2.0 & 1 \\
\hline 36; female & No & 11 & 0 & 1.7 & 1 \\
\hline 29; female & Yes & 8 & 0 & 1.1 & 0 \\
\hline
\end{tabular}

Differences between obese patients and controls: a $P=0.01 ;$ b $P=0.005$

The differences were not significant between patients who obtained and who did not obtain $>10 \%$ reduction of the initial weight.

Abbreviations: FAT, fatty acid metabolism; $\mathrm{VO}_{2 \text { max }}$ maximal oxygen uptake during exercise training of maximal intensity

the Netherlands). The results were analyzed with Metasoft 3.9 CortexBiophisik software (CortexBiophisik GmbH, Leipzig, Germany). Blood pressure was measured with SunTech Tango (Sun Tech Medical, Morrisville, NC, United States), and electrocardiogram with CardioDirect 12.

The study was approved by the Ethics Committee of the Medical University of Gdańsk, (NKEB/41/2010 and NKEBN/151/2010).

Collection of blood samples In all patients, RNA was isolated from the whole blood, using PAXgene Blood RNA Tubes (Qiagen, Venlo, The Netherlands). All tubes were immediately frozen and stored at $-20^{\circ} \mathrm{C}$ until RNA isolation (maximal period, 2 months). RNA was isolated using PAXgene Blood RNA Kit CE (Qiagen, Venlo, The Netherlands). All RNA samples were stored at $-80^{\circ} \mathrm{C}$ until labelling and hybridization.

Quality and concentration of RNA were determined using 2100 Bioanalyzer (Agilent, Amstelveen, the Netherlands) with the use of RNA 6000 Nano Kit (Agilent). Samples with the RNA integrity number exceeding 7.5 were used for further analysis on expression arrays.

Gene expression Illumina TotalPrep 96 RNA Amplification Kit (Applied Biosystems, Nieuwerkerk ad IJssel, the Netherlands) was used for amplification and labelling of RNA. For each sample, 200 ng of RNA was used. Human HT-12_V3_ expression arrays (Illumina, San Diego, United States) were processed according to the manufacturer's protocol. Slides were scanned immediately using Illumina BeadStation iScan (Illumina, San Diego, California, United States).

Image and data analysis First-line check, background correction, and quantile normalization of the data was performed with Genomestudio Gene Expression Analysis module v 1.0.6 Statistics (Illumina, San Diego, California, United States). Entities containing at least $75 \%$ of samples with the signal intensity value above the 20th percentile in $100 \%$ of the samples in at least 2 groups were included for further analysis.

Data analysis was performed using GeneSpring package version 13.0.0 (Agilent Technologies Santa Clara, California, United States). Genes with a significantly different expression between compared groups were chosen based on a $\log _{2}$-fold change of more than 2 in gene expression and a $t$-test $P$ value of less than 0.05 corrected for multiple testing by Benjamin-Hochberg false discovery rates of less than 0.01 . Functional annotation of genes was described using the Go Process analysis and KEGG pathways with a Genecodis functional annotation web-based tool.

Clinical data for this study were analyzed with Statistica 12.0 (StatSoft, Tulsa, Oklahoma, United States).

RESULTS The study group included 16 participants: 9 obese patients and 7 healthy controls. The demographic data are presented in (TABLE 1).

We analyzed the gene expression profile of obese and lean patients. Additionally, it was analyzed according to the outcome of treatment: participants who gained at least $10 \%$ reduction of their body mass were compared with those who did not achieve such a result. Furthermore, the results were analyzed depending on the CPET results (FAT $\geq 20 \mathrm{~g} / \mathrm{h}$ and $\mathrm{VO}_{2 \max } \geq 1.7 \mathrm{ml} / \mathrm{min}$ ). The cutoff points were selected according to the results in the study group (TABLE 1) and a previous study. ${ }^{26}$ In most patients, FAT values were lower than $20 \mathrm{~g} / \mathrm{h}$ (mean [SD] FAT, 13.65 [7] g/h) and $\mathrm{VO}_{2 \max }$ was lower than $1.7 \mathrm{ml} / \mathrm{min}$ (mean [SD], 1.68 [0.41] g/h). In the control group, the results of FAT typically found in obese individuals were observed in 2 participants, while 1 obese patient had the results typical for healthy controls. $\mathrm{VO}_{2 \max }$ values were typical for healthy controls in 4 obese patients, while 1 healthy individual had the results typically observed for obese patients. Thus, the comparison was made according to the estimated cutoff points for FAT and $\mathrm{VO}_{2 \max }$.

A total of 47323 transcripts were analyzed, of which 32379 had a high quality of RNA and were selected for further analysis. 
TABLE 2 Genes with different expression in obese patients and controls

\begin{tabular}{|c|c|c|c|c|}
\hline $\begin{array}{c}\text { Gene symbol } \\
\text { (Probe ID) }\end{array}$ & Gene & Chromosome & $\begin{array}{l}\text { Fold } \\
\text { change }\end{array}$ & $\begin{array}{c}\text { Corrected } \\
P \text { value }\end{array}$ \\
\hline RPS4Y1 (6100687) & $\begin{array}{l}\text { Ribosomal } \\
\text { protein S4, } \\
\text { Y-linked } 1\end{array}$ & $Y$ & 8.3 & 6.4 v10 ${ }^{-4}$ \\
\hline XIST (1690440) & $\begin{array}{l}\text { X inactive } \\
\text { specific } \\
\text { transcript } \\
\text { (non-protein } \\
\text { coding) }\end{array}$ & $X$ & 3 & 6.4 v10 \\
\hline LOC100133662 & Unknown & Unknown & 4 & 6.4 v10 ${ }^{-4}$ \\
\hline RPS4Y2 & $\begin{array}{l}\text { Ribosomal } \\
\text { protein S4, } \\
\text { Y-linked } 2\end{array}$ & $Y$ & -2.16 & 0.001 \\
\hline
\end{tabular}

TABLE 3 Genes with different expression according to treatment outcome

\begin{tabular}{lllll}
$\begin{array}{l}\text { Gene } \\
\text { symbol } \\
\text { (Probe ID) }\end{array}$ & Gene & Chromosome & Fold change & $\begin{array}{c}\text { Corrected } \\
\text { P value }\end{array}$ \\
$\begin{array}{l}\text { CLEC12A } \\
(3780385)\end{array}$ & $\begin{array}{c}\text { C-type lectin } \\
\text { domain, } \\
\text { family } \\
12 \text { member A }\end{array}$ & 12 & 2.22 (downregulation) & 0.02 \\
& $\begin{array}{l}\text { C-type lectin } \\
\text { domain, } \\
\text { family } \\
12 \text { member A }\end{array}$ & 2.43 (downregulation) & 0.03 \\
$(3170601)$ & & \\
& 12A & & \\
\hline
\end{tabular}

Results of gene expression in healthy controls and obese patients A difference in gene expression higher than 2-fold was observed for the following transcripts: HLA-A29.1, RPS4Y1, XIST, LOC100133 662, RPS26P11, RPS26L, LOC650646, and RPS4Y2. Significant results corrected for multiple testing were observed for 4 transcripts: $R P$ S4Y1, XIST, LOC100133 662, and RPS4Y2. The results are presented in TABLE 2.

Results of gene expression according to treatment outcome A significant difference in gene expression was found for 1751 transcripts, including 8 with fold change > 2: LOC388588, CLEC12A (3780385), RPS4Y1, HBG1, CLEC12A (3170 601), HLA-DRB6, $H B G 2$, and $L O C 100008588$. The correction for multiple testing indicated significant results for 2 transcripts of CLEC12A, which showed lower expression for patients who achieved a significant reduction of body mass ( $>10 \%$ of the initial weight) (TABLE 3 ).

The crucial pathways involving the analyzed transcripts ( $t$ test, $\mathrm{n}=1751$ ) were indicated with functional analysis (Supplementary material, $\mathrm{Ta}$ ble S1).

Results of gene expression according to FAT value A significant difference in gene expression between patients with FAT lower than $20 \mathrm{~g} / \mathrm{h}$ compared with those with FAT of $20 \mathrm{~g} / \mathrm{h}$ or higher was found for 2455 transcripts, including 8 with fold change $>2$ : HLA-A29.1, RPS4Y1, XIST, LOC100133 662, HLA-DRB6, HLA-DRB4, EIF1AY, and RPS4Y2. The correction for multiple testing indicated significant results for the following genes: HLA-A29.1, RPS4Y1, XIST, LOC100133 662, HLA-DRB4, EIF1AY, and RPS4Y2 (TABLE 4).

The crucial pathways involving the analyzed transcripts ( $t$ test, $\mathrm{n}=2455$ ) were indicated with functional analysis (Supplementary material, $\mathrm{Ta}$ ble S2).

Results of gene expression according to $\mathrm{VO}_{2 \max } \mathrm{A}$ significant difference in expression was found for 1742 transcripts, including 6 with fold change $>2$ : HLA-DRB1, FOLR3, RPS4Y1, XIST, LOC100133662, and IFIT1. The correction for multiple testing indicated significant results for 5 genes: HLA-DRB1, RPS4Y1, XIST, LOC100133 662, and IFIT1 (TABLE 5). The crucial pathways involving the analyzed transcripts ( $t$ test, $\mathrm{n}=1742$ ) were indicated with functional analysis (Supplementary material, Table S3).

DISCUSSION Our results showed interesting differences in gene expression related to the CPET results indicating abnormalities in fat oxidation and maximal oxygen uptake. The genes with crucial differences in expression were CLEC12A, genes of the major histocompatibility complex HLA-DRB1, HLA-DRB4, HLA-A29.1, and IFIT1, and a transcript with an unknown function LOC100133662.

A difference in expression of 2 transcripts of the CLEC12A gene was found in patients who achieved a significant reduction of the body mass. The product of the CLEC12A belongs to the family of lectin receptors localized on the surface of myeloid cells, including macrophages. Its role was described in rheumatoid arthritis ${ }^{27}$ and Crohn disease. ${ }^{28}$ Differences in expression of CLEC12A dependent on the patient diet were described. ${ }^{21}$ The apigenin, which is a natural flavonoid, decreases the expression of CLEC12A in dendritic cells. It reduces systemic inflammation related to obesity. ${ }^{21}$ Systemic inflammation is one of significant consequences of obesity. The crucial cells involved in systemic inflammation in obesity are the macrophages..$^{29-31}$ The correlation of the expression of macrophage activation markers and plasma glucose levels, as well as glycated hemoglobin $\mathrm{A}_{1 c}$, was described. ${ }^{9}$ Studies on the Nordic diet showed changes in gene expression. ${ }^{20}$ The diet components may influence the expression of the genes involved in apoptosis, DNA repair, as well as cell proliferation and migration. ${ }^{19,32}$ The higher expression of CLEC12A in patients who did not achieve a body mass reduction in our study may be related to increased inflammation related to obesity, which impairs the muscle function.

The product of the IFIT1 gene is an inflammatory protein. The expression of the gene was higher in patients with lower $\mathrm{VO}_{2 \max }$, which can be related to its role in obesity-related inflammation. The expression of IFIT1 is induced by stimulation with interleukin 6 linked to obesity-related inflammation. ${ }^{33}$ An increase of the IFIT1 expression was also observed in obese patients with 
TABLE 4 Genes with different expression according to FAT $(\mathrm{g} / \mathrm{h})$ results

\begin{tabular}{lllll}
$\begin{array}{l}\text { Gene symbol } \\
\text { (Probe ID) }\end{array}$ & Gene & Chromosome & Fold change & Corrected P \\
value \\
$\begin{array}{l}\text { HLA-A29.1 } \\
\text { (5080692) }\end{array}$ & Major histocompatibility complex & 6 & 3.6 (downregulation) & 0.03 \\
\hline RPS4Y1 (6100687) & Ribosomal protein S4, Y-linked 1 & $\mathrm{Y}$ & 12.7 (downregulation) & 0.005 \\
\hline XIST (1690440) & $\begin{array}{l}\text { X inactive specific transcript (non- } \\
\text {-protein coding) }\end{array}$ & $\mathrm{X}$ & 3.44 (upregulation) & 0.005 \\
\hline LOC100133662 & Unknown & Unknown & 5.6 (downregulation) & 0.004 \\
\hline HLA-DRB4 (7330398) & Major histocompatibility complex & 6 & -3.4 (downregulation) & 0.006 \\
\hline EIF1AY (4150600) & $\begin{array}{c}\text { Eukaryotic translation initiation } \\
\text { factor Y }\end{array}$ & $\mathrm{Y}$ & -2.4 (downregulation) & 0.005 \\
\hline RPS4Y2 (6020273) & Ribosomal protein S4, Y-linked 2 & $\mathrm{Y}$ & -2.67 (downregulation) & 0.001 \\
\hline
\end{tabular}

TABLE 5 Genes with different expression according to $\mathrm{VO}_{2 \max }$ results

\begin{tabular}{|c|c|c|c|c|}
\hline $\begin{array}{l}\text { Gene symbol } \\
\text { (Probe ID) }\end{array}$ & Gene & Chromosome & Fold change & $\begin{array}{l}\text { Corrected } P \\
\text { value }\end{array}$ \\
\hline HLA-DRB1 (5260484) & Major histocompatibility complex & 6 & 3.3 (upregulation) & 0.04 \\
\hline RPS4Y1 (6100687) & Ribosomal protein S4, Y-linked 1 & $\mathrm{Y}$ & 5.1 (downregulation) & 0.04 \\
\hline XIST (1690440) & $\begin{array}{l}X \text { inactive specific transcript (nonprotein } \\
\text { coding) }\end{array}$ & $\mathrm{x}$ & 2.4 (upregulation) & 0.04 \\
\hline LOC100133662 & Unknown & Unknown & 2.9 (downregulation) & 0.04 \\
\hline IFIT1 (2000148) & $\begin{array}{l}\text { Interferon-induced protein with } \\
\text { tetratricopeptide repeats } 1\end{array}$ & 10 & 2.17 (upregulation) & 0.02 \\
\hline
\end{tabular}

asthma. ${ }^{33}$ IFIT1 is also involved in the immune response to a viral infection and is induced by T helper-2 derived cytokines. ${ }^{34}$

Patients with a lower $\mathrm{VO}_{2 \max }$ also presented higher expression of HLA-DRB1. The genes of the major histocompatibility complex were studied in relation to diabetes, hypertension, and coronary artery disease. ${ }^{32}$ The polymorphism of $H L A-D R B 1$ increases the risk of type 2 diabetes. ${ }^{35}$ The gene is localized in the region $6 \mathrm{p} 22$ of chromosome 6 . This area was related with the risk of type 2 diabetes in a recent multicenter genome-wide association study. ${ }^{32}$ Additionally, the genes HLA-A 29.1 and HLA-DRB4, which also showed differences in the analyzed group, are localized in the neighboring 6 p21 region. Genes localized in this part of the genome show high expression in the adipose tissue. ${ }^{36}$

The transcripts RPS4Y1, RPS4Y2, XIST, and EI$F 1 A Y$, which showed a significant difference in expression, are associated with the sex differences in the study group.

The pathway analysis may provide insights into pathophysiological mechanisms related to the differences in gene expression observed in our study. A group of 16 transcripts differentiating patients who achieved a body mass reduction of at least $10 \%$ of the initial body mass, plays a role in the proteins $\mathrm{Gi}$ alpha and $\mathrm{Gs}$ alpha. This pathway is crucial for the adipogenesis and functioning of fat tissue. ${ }^{37}$ It also plays a role in thermogenesis and cold tolerance. ${ }^{37}$ The mutation of the studied genes leads to the development of $\mathrm{Al}-$ bright syndrome, a rare form of genetic obesity. ${ }^{37}$ A group of 17 of the 127 proteins cooperating in the platelet-derived growth factor signaling pathway was identified in the group of genes with differences in expression in the present study. The proteins which are involved in this pathway are an important component of metabolic syndrome. ${ }^{38}$ The integrin as well as Wnt pathways play a role in the adiponectin signal transduction. ${ }^{39,40}$ The pathological imbalance of $\alpha v / \beta 1$ integrin subunits is implicated in obesity. ${ }^{41}$ The comparison of gene expression in patients according to the peak oxygen uptake showed significant differences in the endothelin pathway-a strong vasoconstrictive and atherogenic factor related to obesity and its complications such as hypertension and obstructive sleep apnea. ${ }^{42}$

A crucial step in gene expression is related to RNA isolation. The PAXGene Tubes system used in this study is a standardized method that provides results highly similar to in vivo conditions and reduces the possible errors related to cell sorting and sample storage. It was used, for example, in the Framingham Heart Study, proving the high diagnostic value of the method. ${ }^{22}$

A study analyzing differences in gene expression found in peripheral blood in patients with obesity and metabolic syndrome had been published previously. ${ }^{23}$ This study confirmed differences related to starvation and lipid-lowering diet. ${ }^{23}$ The studies comparing gene expression in peripheral blood with the adipose tissue, liver, and hypothalamus confirmed the high correlation of gene expression related to lipid metabolism, adiponectin, fat tissue metabolism, glucose insulin, and leptin concentrations. ${ }^{23,43,44} \mathrm{Howev}-$ er, the current study did not identify the genes 
that could be used in pharmacogenetics studies. The gene expression studies show the expression at the time of the analysis, which is related to multiple factors, including diet. ${ }^{20,23}$ The current study proved the role of the CLEC12A gene. Further functional studies of this gene are needed.

Gene analyses were part of large cohort studies on lifestyle modification program in obesity performed in the United States: Diabetes Prevention Program ${ }^{45}$ and Look AHEAD. ${ }^{8}$ The analysis of both cohorts was combined and done in a few steps. Based on previous publications of cooperating centers, several genes of interest were identified, the polymorphisms of which might have been related to the effects of treatment and further weight regain. The results on a group of 3597 participants showed that allele Ala 12 of the PPARG gene is related to short- and long-term effects of treatment. The short-term effect was also related to the polymorphism of $L Y$ PLAL1, GNPDA2, and MTCH2 genes. ${ }^{45}$ The long-term effect was related to the polymorphism of NEGR1 and BDNF genes. A further study was performed in a group of 5730 patients including 1724 participants of the Diabetes Prevention Program and 3906 patients from the Look AHEAD study. ${ }^{8}$ A significant difference was shown only in a single gene, MTIF3, whose polymorphism was related to a significant body mass reduction. ${ }^{8}$ A recent Iranian study reported that the polymorphism of the DYRK1B gene may be related to metabolic syndrome. ${ }^{46}$

It is not possible to indicate a set of genes that could be used as pharmacogenetic biomarkers based on the current knowledge in the field.

The current study has some limitations, such as the use of whole blood in the analysis. Nonetheless, our study gives a unique insight into in vivo gene expression. Based on the data by Liu et $\mathrm{al},{ }^{44}$ we can estimate which cell type is responsible for the observed changes in gene expression. Similarly, there are tools for a post hoc extrapolation of mixed-cell population lines in epigenetic studies. ${ }^{47}$ However, in our future studies we are planning to focus on selected cell types and selected genes studied using the quantitative polymerase chain reaction method.

In conclusion, the results of the current study indicate that obesity is linked to a difference in expression of the genes CLEC12A, IFIT1, HLA-DRB1, $H L A-D R B 4$, and HLA-A 29.1, as well as genes involved in platelet-derived growth factor, endothelin, and G-protein signaling pathways. CPET results provide a unique insight into the pathology of obesity. The test can also be used as a predictor of treatment outcomes. The differences in expression may be responsible for the effects of the treatment related to inflammation caused by obesity, which influences the muscles, fat tissue, and fatty acid metabolism.

SUPPLEMENTARY MATERIAL Supplementary material is available with the online version of the article at www.pamw.pl.
CONTRIBUTION STATEMENT MG-N conceived the concept of the study. MG-N, PV, PN, and MN contributed to the design of the research. MG-N, $\mathrm{PN}, \mathrm{MK}, \mathrm{MP}, \mathrm{KG}-\mathrm{H}$, and $\mathrm{AS}$ were involved in data collection. PV and BS contributed to laboratory analysis. MN and MG-N analyzed the data. MG-N, $\mathrm{SM}$, and $\mathrm{PN}$ coordinated funding for the project. All authors edited and approved the final version of the manuscript.

OPEN ACCESS This is an Open Access article distributed under the terms of the Creative Commons Attribution-NonCommercial-ShareAlike 4.0 International License (CC BY-NC-SA 4.0), allowing third parties to copy and redistribute the material in any medium or format and to remix, transform, and build upon the material, provided the original work is properly cited, distributed under the same license, and used for noncommercial purposes only. For commercial use, please contact the journal office at pamw@mp.pl.

\section{REFERENCES}

1 Eze IC, Schaffner E, Fischer E, et al. Long-term air pollution exposure and diabetes in a population-based Swiss cohort. Environ Int. 2014; 70: 95-105.

2 World Health Organization. Obesity and overweight. Key facts. http:// www.who.int/mediacentre/factsheets/fs311/en/. Accessed February 25, 2018.

3 Doryńska A, Polak M, Kozela M, et al. Cardiovascular disease (CVD) risk factors in Kraków and in the whole Poland adult population. Results from the WOBASZ study and Polish arm of the HAPIEE project. Przeg Epidemiol. 2015; 69: 79-86.

4 Stepaniak U, Micek A, Waśkiewicz A, et al. Prevalence of general and abdominal obesity and overweight among adults in Poland. Results of the WOBASZ II study (2013-2014) and comparison with the WOBASZ study (2003-2005). Pol Arch Med Wewn. 2016; 126: 662-671.

5 Lim SS, Vos T, Flaxman AD, et al. A comparative risk assessment of burden of disease and injury attributable to 67 risk factors and risk factor clusters in 21 regions, 1990-2010: a systematic analysis for the Global Burden of Disease Study 2010. Lancet. 2012; 380: 2224-2260. ए]

6 Lu Y, Hajifathalian K, Ezzati M, et al. Metabolic mediators of the effects of body-mass index, overweight, and obesity on coronary heart disease and stroke: a pooled analysis of 97 prospective cohorts with 18 million participants. Lancet. 2014; 383: 970-983.

7 Executive summary: Guidelines (2013) for the management of overweight and obesity in adults: a report of the American College of Cardiology/ American Heart Association Task Force on Practice Guidelines and the Obesity Society published by the Obesity Society and American College of Cardiology/American Heart Association Task Force on Practice Guidelines. Based on a systematic review from the The Obesity Expert Panel, 2013. Obesity (Silver Spring). 2014; 22 Suppl 2: 5-39.

8 Papandonatos GD, Pan 0, Pajewski NM, et al. genetic predisposition to weight loss and regain with lifestyle intervention: analyses from the Diabetes Prevention Program and the Look AHEAD Randomized Controlled Trials. Diabetes. 2015; 64: 4312-4321.

9 Unick JL, Beavers D, Jakicic JM, et al. Effectiveness of lifestyle interventions for individuals with severe obesity and type 2 diabetes: results from the Look AHEAD trial. Diabetes Care. 2011; 34: 2152-2157.

10 Burguera $B$, Jesús Tur $\mathrm{J}$, Escudero $A J$, et al. An intensive lifestyle intervention is an effective treatment of morbid obesity: The TRAMOMTANA Study-A Two-Year Randomized Controlled Clinical Trial. Int J Endocrinol. 2015; 2015: 194696.

11 Apovian CM, Aronne LJ, Bessesen DH, et al. Pharmacological management of obesity: an endocrine Society clinical practice guideline. J Clin Endocrinol Metab. 2015; 100: 342-362. ¿

12 Smith SM, Meyer M, Trinkley KE. Phentermine/topiramate for the treatment of obesity. Ann Pharmacother. 2013; 47: 340-349. $\square$

13 Puzziferri N, Roshek TB, Mayo HG, et al. Long-term follow-up after bariatric surgery: a systematic review. JAMA. 2014; 312: 934-942. ¿

14 Fried M, Yumuk V, Oppert JM, et al. Interdisciplinary European guidelines on metabolic and bariatric surgery. Obes Surg. 2014; 24: 42-55.

15 Kanaley JA, Weatherup-Dentes MM, Alvarado CR, et al. Substrate oxidation during acute exercise and with exercise training in lean and obese women. Eur J Appl Physiol. 2001; 85: 68-73. ¿ 
16 Lazzer S, Busti C, Agosti F, et al. Optimizing fat oxidation through exercise in severely obese Caucasian adolescents. Clin Endocrinol (0xf). 2007; 67: 582-588.

17 Stankala S, Zielińska D, Mrowiec J, et al. [Ergospirometry use in cardiovascular diseases]. Kardiol Pol. 2008; 66: 1135-1139. Polish.

18 Straburzyńska-Migaj E. [Ergospirometry in clinical practice]. Warsaw, Poland: Wydawnictwo Lekarskie PZWL; 2010. Polish.

19 Wang L, Gao S, Jiang W, et al. Antioxidative dietary compounds modulate gene expression associated with apoptosis, DNA repair, inhibition of cell proliferation and migration. Int J Mol Sci. 2014; 15: 16 226-16245.

20 Fritzen AM, Lundsgaard AM, Jordy AB, et al. New Nordic diet-induced weight loss is accompanied by changes in metabolism and AMPK signaling in adipose tissue. J Clin Endocrinol Metab. 2015; 100: 3509-3519.

21 Ginwala R, McTish E, Raman C, et al. Apigenin, a natural flavonoid, attenuates EAE severity through the modulation of dendritic cell and other immune cell functions. J Neuroimmune Pharmacol. 2015; 11: 36-47.

22 Joehanes $\mathrm{R}$, Johnson $\mathrm{AD}$, Barb $\mathrm{JJ}$, et al. Gene expression analysis of whole blood, peripheral blood mononuclear cells, and lymphoblastoid cell lines from the Framingham Heart Study. Physiol Genomics. 2012; 44: 59-75. ¿

23 Reynés $\mathrm{B}$, Díaz-Rúa $\mathrm{R}$, Cifre $\mathrm{M}$, et al. Peripheral blood mononuclear cells as a potential source of biomarkers to test the efficacy of weight-loss strategies. Obesity (Silver Spring). 2015; 23: 28-31.

24 Oliver $P$, Reynés $B$, Caimari A, et al. Peripheral blood mononuclear cells: a potential source of homeostatic imbalance markers associated with obesity development. Pflügers Arch. 2013; 465: 459-468.

25 Altman DG, ed. Practical Statistics for Medical Research. London, United Kingdom: Chapman and Hall/CRC; 1991.

26 Gruchała-Niedoszytko M, Niedoszytko M, Sanjabi B, et al. Analysis of the differences in whole-genome expression related to asthma and obesity. Pol Arch Med Wewn. 2015; 125: 722-730.

27 Redelinghuys $\mathrm{P}$, Whitehead $\mathrm{L}$, Augello A, et al. MICL controls inflammation in rheumatoid arthritis. Ann Rheum Dis. 2016; 75: 1386-1391.

28 Begun J, Lassen KG, Jijon HB, et al. Integrated genomics of Crohn's disease risk variant identifies a role for CLEC12A in antibacterial autophagy. Cell Rep. 2015; 11: 1905-1918.

29 Dib LH, Ortega MT, Fleming SD, Melgarejo T. Bone marrow leptin sig naling mediates obesity-associated adipose tissue inflammation in male mice. Endocrinology. 2014; 155: 40-46. ¿־

30 Fink LN, Oberbach A, Costford SR, et al. Expression of antiinflammatory macrophage genes within skeletal muscle correlates with insulin sensitivity in human obesity and type 2 diabetes. Diabetologia. 2013; 56: $1623-1628$.

31 Perreault M, Zulyniak MA, Badoud F, et al. A distinct fatty acid profile underlies the reduced inflammatory state of metabolically healthy obese individuals. PLoS One. 2014; 9: e88539.

32 Palmer ND, Goodarzi MO, Langefeld CD, et al. Genetic variants associated with quantitative glucose homeostasis traits translate to type 2 diabe tes in Mexican Americans: The GUARDIAN (Genetics Underlying Diabetes in Hispanics) Consortium. Diabetes. 2015; 64: 1853-1866.

33 McManus DD, Beaulieu LM, Mick E, et al. Relationship among circulating inflammatory proteins, platelet gene expression, and cardiovascular risk. Arterioscler Thromb Vasc Biol. 2013; 33: 2666-2673.

34 Herbert C, Zeng QX, Shanmugasundaram R, et al. Response of airwa epithelial cells to double-stranded RNA in an allergic environment. Trans Respir Med. 2014; 2: 11.

35 Williams RC, Muller YL, Hanson RL, et al. HLA-DRB1 reduces the risk of type 2 diabetes mellitus by increased insulin secretion. Diabetologia. 2011 54: 1684-1692.

36 Yang YS, Song HD, Shi WJ, et al. Chromosome localization analysis of genes strongly expressed in human visceral adipose tissue. Endocrine. 2002; 18: 57-66. ¿

37 Chen $\mathrm{M}$, Chen $\mathrm{H}$, Nguyen $\mathrm{A}$, et al. G(s)alpha deficiency in adipose tissue leads to a lean phenotype with divergent effects on cold tolerance and diet-induced thermogenesis. Cell Metab. 2010; 11: 320-330.

38 Shim U, Kim HN, Sung YA, et al. pathway analysis of metabolic syndrome using a genome-wide association study of Korea Associated Resource (KARE) Cohorts. Genomics Inform. 2014; 12: 195-202.

39 Adi N, Perriotte-Olson C, V Desouza C, et al. Hematopoietic cyclooxygenase-2 deficiency increases adipose tissue inflammation and adiposity in obesity. Obesity (Silver Spring). 2015; 23: 2037-2045.

40 Ramezani-Moghadam M, Wang $\mathrm{J}$, Ho $\mathrm{V}$, et al. Adiponectin re duces hepatic stellate cell migration by promoting tissue inhibito of metalloproteinase-1 (TIMP-1) secretion. J Biol Chem. 2015; 290: 5533-5542. ¿

41 Chen 0 , Shou P, Zhang L, et al. An osteopontin-integrin interaction plays a critical role in directing adipogenesis and osteogenesis by mesenchymal stem cells. Stem Cells. 2014; 32: 327-337.

42 Carratù $P$, Ventura VA, Maniscalco $M$, et al. Echocardiographic finding and plasma endothelin-1 levels in obese patients with and without obstructive sleep apnea. Sleep Breath. 2016; 20: 613-619.
43 Kim AY, Park YJ, Pan X, et al. Obesity-induced DNA hypermethylation of the adiponectin gene mediates insulin resistance. Nat Commun. 2015 6: 7585.

44 Liu H, Xu R, Liu X, et al. Bioinformatics analysis of gene expression in peripheral blood mononuclear cells from children with type 1 diabetes in 3 periods. Exp Clin Endocrinol Diabetes. 2014; 122: 477-483. [

45 Delahanty LM, Pan 0 , Jablonski KA, et al. Genetic predictors of weight loss and weight regain after intensive lifestyle modification, metformin treatment, or standard care in the Diabetes Prevention Program. Diabetes Care. 2012; 35: 363-366. ك

46 Keramati AR, Fathzadeh M, Go GW, et al. A form of the metabolic syndrome associated with mutations in DYRK1B. N Engl J Med. 2014:370: 1909-1919. ¿

47 Potaczek DP, Harb H. Michel S, et al. Epigenetics and allergy: form basic mechanisms to clinical applications. Epigenomics. 2017; 9: 539-571. 